\title{
PREVALENCE OF TINEA CAPITIS INFECTION AMONG PRIMARY SCHOOL CHILDREN IN NKANU WEST LGA OF ENUGU STATE NIGERIA.
}

\section{Ogu, E. O., Ogunbodede, T.T., Iloputaife, E.J}

Department of Applied Microbiology and Brewing, Enugu State University of Science and Technology, Enugu Nigeria. P.M.B. 01660, Enugu, Nigeria Correspondence: oguemmaesq@yahoo.co.uk and temitopetitus16@gmail.com

Tinea infection is a common fungal infection that affects the superficial keratinized tissues of the body (skin, hair and nails). This study assessed Tinea infections among primary schools in Nkanu-West Local Government Area of Enugu State, Nigeria. Seven primary schools were selected for the study. Ethical approval was obtained from the Education and Health Departments of Nkanu-West Local Government and informed consent obtained from parents of the pupils. A researcher-developed questionnaire was used to obtain information on demography, hygienic practices and clinical picture. The pupils were randomly selected based on those with Tinea (ringworm) lesions. Samples of nail clippings, hair and skin scrapings were collected from the affected sites after sterilizing with $70 \%$ ethanol unto sterile wide containers and transported to the Laboratory section of the Department of Applied Microbiology and Brewing, Enugu State University of Science and Technology, Enugu. The samples were analyzed by microscopy using $10 \% \mathrm{KOH}$ followed by mycological cultures using Sabourand dextrose agar, Potato dextrose agar and Corn meal agar. The isolates were identified based on their colonial morphology using lactophenol cotton blue stain. Statistical analysis was done by chi-square and students t-test. Out of the 1,544 pupils examined, 186 had various Tinea infections; Tinea capitis was the commonest infection with a prevalence of 72.5\%. Tinea corporis, Tinea unguin and Tinea mannum had a prevalence of $16.18 \%, 3.8 \%$ and $2.2 \%$ respectively. The males had higher isolates of dermatophytes $(55.1 \%)$ than the females $(44.9 \%)$. The age group of 6 to 10 years had the highest fungal isolates of $55.4 \%$ with the least isolates seen in those below 6 years; $11.8 \%$. The mean age for the pupils was $8.70+$ + 2.66. There was no significant difference $(\mathrm{p} \leq 0.05)$ between the age groups. Trichophyton mentagrophtes was the leading dermatophyte isolated; $56.1 \%$ and the least was Trichophyton soudanese with a yield of $0.5 \%$. The non-dermatophyte species isolated were Aspergillus flavus $(0.5 \%)$ and Candida albicans (1.6\%). Risk factors assessed such as poor personal hygiene, overcrowding, intimate association with household pests among the children and poor infrastructure play roles in the dissemination of Tinea infection among these children. Consequently, proper health education, personal and environmental sanitation, provision of infrastructure, primary health care and regular clinical studies are recommended for these primary school pupils.

\section{Introduction}

Tinea capitis is a dermatophyte infection. It is a common skin disorder ranked amongst the top five diseases seen at dermatology clinics across Nigeria. Tinea capitis, the most common dermatophytoses in children is an infection of the scalp and hair shaft. Transmission can be anthropophilic, zoophilic and geophilic.Transmission of Tinea capitis is enhanced by poor hygiene, overcrowding, contaminated hats, brushes, pillows and other inanimate objects.Clinical presentation depends on the geographical location, immunity of the host, prevailing organisms in the environment and mode of transmission (Olusola etal., 2014). 
Tinea infections are fungal infections caused by dermatophytes- a unique group of fungi that invade and grow on dead keratin. Superficial mycoses are among the most frequent forms of human infections, being estimated to affect about $15 \%$ of the world s population, and their incidence is constantly increasing (Havlickovaet al., 2008). Dermatophytes represent the prevailing type of fungi that cause these infections of the hair, skin and nails (Havlickovaet al., 2008). Three types of dermatophytes account for the majority of infections: Epidermophyton, Trichophyton, and Microsporum (Bologniaet al., 2007). Emmons separated them in 1934 based on differences in the macroconidia (Ajello, 1968). Tinea infections have varied presentations, are named by location, and have similar treatments (Noble et al., 1998).Dermatophytes have acquired in the evolutionary process the ability to metabolize and subsist upon keratin (they require keratin for nutrition), a protein resistant to most other organisms. They produce keratinase, which enables them to use keratin as a nutrient source. The fungi attack hair,skin and nails, where keratin is the major structural protein; leading to a wide range of disease states (Bologniaet al., 2007). Infection is limited to the dead layers of the skin but encouraged by a damp and warm local environment. They tend to grow outwards on skin, producing a ring like pattern hence the term 'ringworm' (Achtermanand White, 2012). Ringworm infection is not a reportable disease but is a cause for concern because of its contagious nature.

The aim of the study was to determine the prevalence and causative agents of Tinea capitis; and the predisposing factors among primary school students in Nkanu West LGA, Enugu state, Nigeria.

\section{MATERIALS AND METHODS}

The study was conducted at Nkanu-West Local Government Area of Enugu State among primary school children. Study sites consisted of five communities in the area namely; Agbani, Umueze, Obe, Akpugo and Ozalla. Farming is the major means of livelihood here. A systematic primary school based assessment of Tinea infections has not been conducted in this area. Primary school children selected randomly from primary schools in accessible areas were used for the study.

A total of 186 primary school children were recruited from the general population of 1,544 pupils for the study by purposive sampling. The sample size was calculated using the WHO standard formula of year 2009 and the proportion used was 15\%, based on previous studies on the prevalence of Tinea infections (Olaideet al., 2014). The pupils were selected based on those with physical appearance of Tinea infections (erythema, alopecia, scaling, crusting, circinate lesion or follicular inflammation, pruitis). In addition, those selected for the study were not above 12 years of age. This was because the study considered only primary school children and Tinea infections are more rampant among these set of individuals. The pupils that did not show obvious signs of Tinea infections were excluded from the study. In addition, non-primary school children were excluded from the study and those on antifungal treatment, orthodox or traditional, 2 weeks to the period of study. The selection of participants was with the permission of the headmaster/headmistress. Informed consent was obtained from the pupils. This was based on the agreement that the participant's anonymity must be maintained, good laboratory practice/quality control ensured that every finding treated with utmost confidentiality and for the purpose of the study only. The sampling method used here is the probability method. By random sampling method, twelve primary schools were selected for this study.

A total of 186 children with an age range of 4-12 years suspected to have Tinea infections (because of the obvious signs) were selected from the primary schools. Before examination and sample collection, the teachers and pupils were educated on the objective of the study; including the nature of Tineainfections, clinical features, laboratory diagnosis and mode of 
transmission. Questionnaires and physical observations were used to obtain information on the source of water, number of times uniforms and stockings are washed in a week, number of times these children take their bath in a day, frequency of barbing of hair, the type of domestic animals they keep and contact with these animals, skin lesions and duration, clinical picture, prior therapy as well as demographic data. The final selected positive samples for this study were 176 samples comprising of $55.1 \%$ males and $44.9 \%$ females.

Table 1: Distribution of pupils according to schools

\begin{tabular}{|c|c|c|}
\hline Name of primary school & $\begin{array}{l}\text { Total number of } \\
\text { pupils in the } \\
\text { school }\end{array}$ & $\begin{array}{l}\text { Number of pupil } \\
\text { with Tinea } \\
\text { lesions }\end{array}$ \\
\hline Central School Agbani & 128 & 18 \\
\hline Community Primary School Obe & 153 & 27 \\
\hline Community Primary School Umueze & 155 & 16 \\
\hline Community Primary School Ozalla & 115 & 21 \\
\hline Group School Agbani & 124 & 11 \\
\hline Mea-Mata Nursery and Primary School & 111 & 6 \\
\hline Saint John Primary School Agbani & 119 & 8 \\
\hline Holy Family Nursery and Primary School Agbani & 138 & 20 \\
\hline Lovely Kids Nursery and Primary School Agbani & 116 & 13 \\
\hline King Kids Nursery and Primary School Agbani & 102 & 12 \\
\hline Eagle's Flight Nursery and Primary School Agbani & 147 & 19 \\
\hline Westview Nursery and Primary School Agbani & 136 & 15 \\
\hline Total & 1544 & 186 \\
\hline
\end{tabular}

\section{Sample Collection}

Physical examination of pupils was conducted to identify features suggestive of Tinea infections. The skin, head, hands and nails were carefully examined for characteristic features.

Two samples collection methods were used in this study. In the first method, samples consisting of epidermal scales, crusts and infected hairs and nail clippings were scrapped from the active edge of lesions in the infected sites using sterile scalpel blades following cleansing of infected sites with $70 \% \mathrm{v} / \mathrm{v}$ ethanol. The scrapings were collected in sterile wide containers. The samples were divided into two portions: one for microscopic examination and the other for culture analysis. The samples were transported to the laboratory section of the Department of Applied Microbiology and Brewing, Enugu State University of Science and Technology, Enugu State, Nigeria, and immediately subjected to microscopic and culture analysis. A second method was a brush culture technique as described by Mackenzie (1961). This method was used because hair plucks may potentially miss infected hairs and may not sample infected epithelium adequately. With this technique, new toothbrush was removed from its packaging and rubbed gently over the suspected area, including the skin and haired margins of alopeic or scaly lesions for about 1 minute. The unaffected area was brushed first before the lesions so as to avoid spreading spores to unaffected areas and to avoid losing spores from affected areas. The samples were also transported immediately to the same laboratory.

\section{Mycological procedure}

Direct Microscopic Examination

The Direct microscopic examination of scales and broken-off hairs placed on a microscope slide with one or two drops of $10 \%$ potassium hydroxide $(\mathrm{KOH})$ (One drop for skin scales 
and hair plucks and drops for nail clippings) added and covered with a cover slip. This was heated gently over a flame in order to soften and arclear the material and the specimen was examined with low (x10) and high (x40) power objective for the presence of hyphae and/or arthroconidia.

\section{Fungal Culture}

Each scrapping was cultured onto Sabouraud dextrose chloramphenicol actidione agar. The plates were incubated at $280 \mathrm{oc}$ for up to 28 days and examined daily for fungal growth. Fungal isolates were sub cultured unto plates of Sabouraud agar, potato dextrose agar and corn meal agar. The isolates were examined visually and microscopically for morphology of fungi using lactophenol cotton blue by slide culture technique. The slide technique was carried out by:

- A block of Sabouraud agar was aseptically cut and placed on the centre of a slide.

- The four sides of the agar were inoculated with spores or mycelia fragments of the fungi with the loop flamed intermittently.

- Ascetically, a sterile cover slip was placed on the upper surface of the cut agar and the petri dish covered and incubated at room temperature for 48 hours.

- After 48hours, the slide was examined for growth.

- A drop of lactophenol cotton blue stain was placed on a clean slide and the coverslip from the slide culture removed.

- $95 \%$ ethanol was placed on the hyphae on the cover glass and the cover slid was placed mold side down on the drop of lactophenol cotton blue on the slide and examined under the microscope.

\section{Identification of isolates}

The identification was based on morphological characteristics and appearance using lactophenol cotton blue, with the aid of a mycology manual. Candida albicans was further identified using the germ tube test. The germ tube test was carried out by putting $0.5 \mathrm{ml}$ of human serum into a small tube. A colony of the yeast was emulsified in the serum and incubated at $37^{\circ} \mathrm{C}$ for 2 hours. A drop of the serum was transferred to a slide and examined for production of germ tubes. Aspergillus flavus was identified by the nature of its conidia and conidiophores.

\section{Data Analysis}

The data was subjected to descriptive statistics and analyzed using Chi-square and student's t-test. Probability value of less than or equal to 0.05 were considered statistically insignificant.

\section{RESULTS}

A total of 1544 pupils were examined for the presence of Tinea infections in seven primary schools in Nkanu-West Local Government Area of Enugu State. Using microscopy and culturing methods, it was observed that out of 186 pupils with obvious signs of the infection, $176(94.6 \%)$ were clinically diagnosed with Tinea infections. Table 1 shows a distribution of the pupils according to the various primary schools visited. Table 2 shows a distribution of the various fungal isolates. Dermatophytes constituted $97.7 \%$ of the samples while nondermatophytes were $2.3 \%$. Concerning the dermatophytes, 2 genus; Trichophyton and Microsporumwere represented with eight different species that included Trichophyton mentagrophytes as the leading organism isolated $(56.1 \%)$. This was followed by Trichophyton rubrum (14\%). Trichophyton soudanesewas the least dermatophyte specie isolated $(0.5 \%)$. Other isolates in this study were Trichophyton tonsurans, Trichophyton 
schoenleinii, Microsporumaudouinii, Microsporumgypseum, Microsporumcanisand Trichophyton sudanese. The non-dermatophytes isolated were Candida albicans (1.6\%) and Aspergillus flavus (0.55).

Table 3 depicts the distribution of dermatophytes according to sites. Tinea capitis was the commonest accounting for $72.5 \%$ of the prevalence. Tinea corporis, Tinea ungium (onychomycosis) and Tinea mannum had a prevalence of $16.18 \%, 3.8 \%$ and $2.2 \%$ respectively.

Table 4 shows the relationship between the demography and risk factors in acquiring Tinea infections. The males had higher isolates of dermatophytes $(55.1 \%)$ as against $44.9 \%$ in the females. The age group of 6 to 10 years had the highest fungal isolates of $55.4 \%$ with the least isolates seen in those below 6 years of age; $11.8 \%$. Risk factors assessed such as poor personal hygiene, overcrowding and intimate association with household pets among the children were the suspected sources of Tinea infections.

Table 2: Distribution of the Various Fungal Isolates

\begin{tabular}{ll}
\hline Type of fungi & $\mathbf{f}(\%)$ \\
\hline Trichophytonmentagrophytes & $105(56.1 \%)$ \\
Trichophytonrubrum & $26(14 \%)$ \\
Trichophytontonsurance & $23(12.2 \%)$ \\
Trichophytonschoenleinii & $7(3.7 \%)$ \\
Microsporumaudouinii & $4(2.2 \%)$ \\
Microsporumgypseum & $4(2.2 \%)$ \\
Microsprumcanis & $2(1.1 \%)$ \\
Trichophytonsoudanese & $1(0.5 \%)$ \\
Candida albicans & $3(1.6 \%)$ \\
Aspergillus flavus & $1(0.5 \%)$ \\
\hline
\end{tabular}

Table 3: Distribution of Dermatophytes According to Sites

\begin{tabular}{|c|c|c|c|c|}
\hline $\begin{array}{l}\text { Site of } \\
\text { infection }\end{array}$ & $\mathbf{N}$ & Fungal isolate & $\mathbf{f}(\%)$ & $\begin{array}{l}\text { Type of Tinea } \\
\text { infection }\end{array}$ \\
\hline Head & 135 & $\begin{array}{l}\text { Trichophytonmentagrophytes } \\
\text { Trichophytonschoenleinii } \\
\text { Microsporumcanis } \\
\text { Candida albicans } \\
\text { Trichophytontonsurans } \\
\text { Microsporumaudouinii } \\
\text { Microsporumgypseum }\end{array}$ & $\begin{array}{l}95(51.1 \%) \\
7(3.8 \%) \\
1(1.05 \%) \\
2(1.1 \%) \\
22(11.8 \%) \\
4(2.2 \%) \\
4(2.2 \%)\end{array}$ & Tinea capitis $(72.5 \%)$ \\
\hline Nail & 7 & $\begin{array}{l}\text { Trichophyton mentagrophytes } \\
\text { Trichophyton rubrum }\end{array}$ & $\begin{array}{l}1(0.5 \%) \\
6(3.2 \%)\end{array}$ & Tinea capitis $(3.8 \%)$ \\
\hline Skin & 30 & $\begin{array}{l}\text { Trichophyton mentagrophytes } \\
\text { Aspergillus falvus } \\
\text { Trichophyton soudanese } \\
\text { Trichophyton rubrum } \\
\text { Microsporumaudouinii }\end{array}$ & $\begin{array}{l}11(5.9 \%) \\
1(0.5 \%) \\
1(0.5 \%) \\
16(8.6 \%) \\
1(0.5 \%)\end{array}$ & Tinea capitis $(16.1 \%)$ \\
\hline Hand & 4 & $\begin{array}{l}\text { Trichophyton mentagrophytes } \\
\text { Candida albicans } \\
\text { Trichophyton rubrum }\end{array}$ & $\begin{array}{l}1(0.5 \%) \\
1(0.5 \%) \\
2(1.1 \%)\end{array}$ & Tinea capitis $(2.2 \%)$ \\
\hline
\end{tabular}


Table 4: Relationship between the Demography and Risk Factors in Acquiring Tinea capitis

\begin{tabular}{|c|c|c|c|}
\hline Variable & $\mathbf{N}$ & Number of isolates & p-Values \\
\hline Sex: & & & 0.523 \\
\hline Male & 102 & $97(55.1 \%)$ & \\
\hline Female & 84 & $79(44.9 \%)$ & \\
\hline Age: & & & 0.804 \\
\hline$<6$ & 23 & $22(11.8 \%)$ & \\
\hline $6-10$ & 110 & $103(55.4 \%)$ & \\
\hline$>10$ & 53 & $51(27.4 \%)$ & \\
\hline $\begin{array}{l}\text { Number of times school uniform is } \\
\text { washed in a week: }\end{array}$ & & & 0.74 \\
\hline $1-2$ times & 128 & $118(67 \%)$ & \\
\hline Less than once & 58 & $58(33 \%)$ & \\
\hline $\begin{array}{l}\text { Number of times stockings are wasl } \\
\text { in a week: }\end{array}$ & & & 0.67 \\
\hline $1-2$ times & 78 & $74(42.05 \%)$ & \\
\hline Less than once & 65 & $59(33.5 \%)$ & \\
\hline *Others do not wear at all & 43 & $43(24.4 \%)$ & \\
\hline $\begin{array}{l}\text { Number of times bathing is done in } \\
\text { day: }\end{array}$ & & & 0.65 \\
\hline Once a day & 41 & $41(23.3 \%)$ & \\
\hline Twice a day & 145 & $135(76.7 \%)$ & \\
\hline Keeping/tending to animals: & & & 0.95 \\
\hline Yes & 83 & $83(47.2 \%)$ & \\
\hline No & 103 & $93(52.8 \%)$ & \\
\hline Use of streams with animals: & & & 0.46 \\
\hline Yes & 50 & $50(28.4 \%)$ & \\
\hline No & 136 & $126(71.6 \%)$ & \\
\hline Recurrent/re-infection: & & & $<0.01$ \\
\hline Yes & 68 & $68(38.6 \%)$ & \\
\hline No & 118 & $108(61.4 \%)$ & \\
\hline
\end{tabular}

\section{DISCUSSION}

Tinea infections are common and remain an important public health problem among children worldwide and particularly in tropical regions (Akinboroet al., 2013; Ajao and Akintude, 1985).

It is evident in this study that the prevalence of Tinea infections was $12.1 \%$. This is lower than in some previous studies (Ogbuet al., 2015) but higher than that of Enemuor and Amedu in Northen Nigeria (Enemuor and Amedu, 2009) and that of Adefemiet al., in Kwara State (Adefemiet al., 2011). However, the low prevalence rate in this study was unexpected as all parameters known to favour persons transmission, such as the presence of previous skin lesions, overcrowding in the home, practice of sharing personal belonging, practice of keeping and tending animals and factors that suggest poor personal hygiene are present in the pupils surveyed. This might not be unconnected to the use of traditional remedies whose mechanism of action are unknown, by some of the respondents to treat lesions and this may perhaps have altered invitro isolation of dermatophytes.

In this study, Tinea infections were recorded in pupils examined in seven primary schools in Nkanu-West Local Government Area of Enugu State. This indicates that this infection is 
endemic in this part of the world where school age children were at greater risk of infection due to absence of control measures (Enemuor and Amedu, 2009).

The risk factor associated with high prevalence of Tinea infections in this study is improper treatment of previous infection that leads to reinfection of the pupils infected. This maybe as a result of the use of inappropriate antifungal agent or recourse or probably use of herbs in such treaments (Okafor et al., 2001; Nwezeet al., 2004). Other risk factors assessed such a poor hygiene, overcrowding and intimate association with household pets among the children were the suspected sources of infection.

In a similar report, Enemour and Amedu (2009) showed that Tinea infection is a public health problem in tropical countries due to conducive climate environment, which favors their persistence and variability. This study is also similar to those recorded among primary school children in Ebonyi, South Eastern Nigeria (Anosikeet al., 2005). Similar studies in Iraq and Egypt had a low prevalence of $2.7 \%$ and 7.4respectively (Fathi and Al-Samarai, 2000). It has been suggested that differences in the prevalence of Tinea infections in different regions may be due to variation in climatic and environmental conditions of the areas being studied (Ogbonna et al., 1995; Akinboroet al., 2013).

This study showed that Tinea infections are commoner in males $(55.1 \%)$ than females (44.9\%). Males usually keep short hair, visit the barber's shop more, more frequent contact with playmates, play with sand more and are less concerned about hygiene and personal grooming than females (Soyinka, 1978). In addition, females usually weave their hair and visit the barbers less, and practice general personal and hair hygienic management more. This male predominance was also observed in previous studies (Halickova et al., 2008; Ogbonna et al., 1985; Ayanbimpe, 2008).

Tinea infections have a higher prevalence among children less than ten years of age. This is comparable to what Nweze obtained in North- Eastern Nigeria and in other related studies (Nweze and Okafor, 2005; Omar, 2000; Enweaniet al., 1996; Nweze, 2001; Ajao and Akintunde, 1985; Ogunbiyiet al., 2005; Popoola et al., 2006). This affirms the observation that Tinea infection is predominantly a pre-pubertal disease. The prevalence of Tinea infections was observed in all age groups of the pupils, though higher in those between six to ten years old. In addition, the presence of Tinea infections in younger age group supports the suggestion that the infection is related to absence of saturated fatty acids that provide a natural protective mechanism against fungal infections (Fischer and cook, 1998) and children have the least awareness of personal hygiene. This agreed with Ayanbimpeet al. (2008) that attributed the high degree of infection in this age group to the fact that they are more active at the playgrounds and with pets and will thus have closer contact with sources of pathogens and they engage in poor hygienic practices at this age. Other researchers like Omar in Alexandria (Omar, 2000), Figueroa in Southwestern Ethiopia (Figueoraet al., 1997), AdelHafez in sohag governorate (Adel-Hafez, 1997) as well as Venugopal and Venugopal in Saudi Arabia (Venugopal and Venugopal, 1993) have also subscribed to the age difference. It is expected that the younger the age, the poorer will be hygiene and as such more concerned with their outlook and are neater. These reasons are also advanced for the observed preponderance among those aged 10 and younger in this study.

Tinea capitis, a dermatophytosis, was the predominant Tinea infectionrecoreded among primary school pupils in the present study $(72.5 \%)$. This agrees with other studies done in Africa, Europe and Asia (Anosikeet al., 2005; Chepchirchir and Ndinya-Achola, 2009; Omar, 2000; Adefemiet al., 2011). It has been described as the most common paediatric dermatophyte infection among children worldwide (Ajao and Akintunde, 1985; Ogunbiyiet al., 2005; Unekeet al., 2006).

Reasons that can explain the predominance of Tinea capitis among children of primary school age include use of local barbers, poor personal hygiene, short hair that promotes 
transmission from one scalp to the other due to its exposed nature, ignorance and increased frequent contacts with playmates at school and siblings at home (Akinboroet al., 2013; Ogbonna et al., 1985). This explains the high prevalence of the infection observed in this study. It indicates the need for early diagnosis, because it may result in destruction of hair loss and scarring alopecia if left untreated.

Tinea corporis is the next common type of Tinea infection in this area. The disease remains endemic in Nigeria, largely because of lack of information on its prevalence and the absence of control measures (Olaideet al., 2014). In this present study, Tinea corporis was found to have a prevalence of $16.1 \%$ and this is comparable to the result observed in a study of primary school children in Northern Ebonyi of Ebonyi State, Nigeria (Anosikeet al., 2005).

The prevalence and distribution of Tinea corporis in this study is relatively high compared with either the report of Ajao et al. (1985) among primary school children in Ile-Ife, Nigeria $(14.02 \%)$ or those of Omar (2000) in Alexandria (7.4\%).

Other Tinea infections such as Tinea unguim (onychomycosis) and Tinea mannum had a low prevalence rate of $3.8 \%$ and $2.2 \%$ respectively. This is corroborated by previous studies that show these infections to be uncommon in the age group being studied, as they are not usually exposed to predisposing factors such as involvement in gardening (Degreef, 2008; Oyeka and Eze, 2008).

There were no cases of Tinea barbae, Tinea pedis (athlete foot) and Tinea cruris found in this study. This is probably due to the age group being studied. These have been found in older age group as documented by Moon et al. (2001). It is also believed that the older age groups are more likely to grow and trim their beards, wear their shoes more constantly, and wear tight underwear. This, with the hot and humid environment promotes moisture, which will favor susceptibility to the infection (Soyinka, 1978).

The dermatophyte species isolated in this study amounted to $94.6 \%$ as against $5.4 \%$ nondermatophyte species. This suggests that fungal infections generally are still much present within the locality surveyed. Reports on non-dermatopytic fungi associated with dermatophytoses, etiological agents and control of their spread are scanty (Oyeka and Okoli, 2003; Vonshaket al., 2003; Mbata and Nwajagu, 2007). Dermatophytes isolated in this study belonged to the two genera: Trichophyton and microsporum. The genus Trichophyton was the most significant isolate, which agrees with other studies done in developing countries, in Africa continent and parts of Asia (Enemuor and Amedu, 2009; Chepchirchir and NdinyaAchola, 2009; Schmelleret al., 1997). Trichophytonmentagrophytes was the commonest specie isolated followed by Trichophytonrubrum. Others includeTrichophytontonsurans, Trichophytonschoenleinii,

Trichophytonsoudanese, Microsporumaudouinit

Microsporumgypseum, and Microsporumcanis. The non-dermatophyte species included Candida albicans and Aspergillus flavus. Most of the species were more predominant in the males. Studies have established variability in the species of dermatophytes isolated from one geographical region to the other and per time (Ayanbimpe, 2008). In Nigeria, Nweze documented that the spectrum of pathogens and their clinical presentations in West Africa are different from those seen in other continents (Nweze, 2010).

Trichophytonmentagrophyteswas the commonest dermatophyte specie isolated (56.1\%) from the head, skin nail and hand. This is comparable to the findings of Ayanlowo that this fungus is predominant in children (Ayanlowo, 2014) and Adefemietal., (Adefemiet al., 2011). The fungus is said to be cosmopolitan, and is one of the most common dermatophytes infecting man and animals (Hainer, 2003). The presence of Trichophyton rubrum (14.5\%) mostly isolated from the skin of pupils was an indication of poor hygiene and/or overcrowding at homes. Presence of non-dermatophytes such as Candida albicans and Aspergillus flavus is becoming increasing common, one of the factors attributed is the ubiquitous nature of their 
spores in our environment, and that makes it to be carried transiently on healthy skin (Adefemiet al., 2011; Chepchirchiret al., 2009). These non-dermatophytes isolated concurred with the reports of Rahbar et al. (2010), Mbata, and Nwajagu (2007) as well as implied that non-dermatophytic fungi (yeast and conidial forms) synergy with dermatophytic fungi in a yet undefined phenomenal interaction to cause symptomatic superficial fungal interactions across a range of human and animal hosts.

Poor infrastructures such as desks, classrooms may be a contributing factor to the prevalence of Tinea infections among primary school pupils in Nkanu-West Local Government Area of Enugu State since some of the schools assessed Lacked standard studying accommodation as well as recreational facilities. Some children who sit on uncemented floors can contact the infection directly from the soil. This collaborates with the work of Ogbonna et al. (1985).

Two children had multiple site infection (Tinea capitis and Tinea corporis). This finding is also observed in most local and international studies, especially those studies that looked at other sites of the body (Nweze, 2001; Bergson and Fernandez, 2001; Lariet al., 2005). The reason for this multiple site infection might be related to the ability of some strains of dermatophyte to affect more than one site concurrently in the same person.

\section{CONCLUSION}

The prevalence of Tinea infections among primary school children in Nkanu-West Local Government Area of Enugu State is $12.1 \%$. Hence, Tinea infections are a public health problem among the primary school children studied. Tinea capitis was the commonest clinical variety encountered and Trichophyton mentagrophytes was the organism most frequently isolated. This study also confirmed the observations of other researchers that prevalence of Tinea infections is influenced not only by age but also by sex (Fathi and AlSamarai, 2000). The researcher has recommended that constant monitoring; treatment and evaluation of infection in the area and in other primary schools in the country should be encouraged. There should be routine inspection of schoolchildren. Sharing of unhygienic personal belongings with the infected pupils and intimate association with pet animals could increase the mode of transmission. This should be discouraged. Regular health education about fungal infections that highlight their morbidities and modes of spread, should be given to these schoolchildren, their parents and teachers, in order to truly reduce the prevalence and burden of Tinea infections in the area. In addition, there should be provision of good infrastructures in schools by Government, especially in schools where pupils resort to improvised seats or floors. Finally, combined efforts of school-children, teachers, and parents as well as Local, State and Federal government are all required to prevent the prevalence of Tinea capitis infection.

\section{REFERENCES}

1. Achterman, R.R., and White, T.C. (2012). A foot in the door for dermatophyte research. PLOS Patogens, 8(3): e1002564.

2. Addel-Hafez, K. (1997). Adefemi, S.A., Odeigag, L.O. and Alabi, K.M. (2011). Prevalence of demartophytosis among primary school children in Oke-Oyi community of Kwara state. Nigerian Journal of Clinical Practice, 14(1): 23-28.

3. Adefemi, S.A., Odeigah, L.O. and Alabi, K.M. (2011). Prevalence of dermatophytosis among primary school children in Oke-oyi community of Kwara state. Nigerian Journal of Clinical Practice, 14: 23-28.

4. Ajao, A.O. and Akintunde, C. (1985). Studies on the prevalence of Tinea capitis infection in Ile-ife, Nigeria. Mycopathologia, 89(1): 43-48.

5. Ajello, L. (1968). A taxonomic reviewof the demartophytes and related species. Sabouraudia, 6: 147. 
6. Akinboro, A.O., Olasode, O.A., Onayemi, O. and Mejiuni, D.A. (2013). The impact off Tinea capitis on the quality of life: A community based cross sectional study among Nigeria children. Clinical Medicine Insights Dematology, 6: 9-17.

7. Anosike, J.C., Keke, I.R., Uwaezuoke, J.C., Anozie, J.C., Obiukwu, C.E., Nwoke, B.E.B. and Amajuoyi, O.U. (2005). Prevalence and distribution of ring worm infection in primary school children in parts of eastern Nigeria. Journal of Applied Sciences and Environmental Management, 9(3): 21-25.

8. Ayanbimbe, G.M., Taghir, A.D. and Wapwera, S. (2008). Tinea capitis among primary school children in some part off Nigeria. Mycoses, 51: 336-340.

9. Bolognia, J., Jorizzo, J.L. and Rapini, R.P. (2007). Dermatology ( $2^{\text {nd }}$ Edition). St. Louis, Mosby Elsevier. p: 1135.

10. Brasch, J. (2010). Pathogenesis of Tinea. Journal of DeutschenDermatologischenGasellschaft, 8(10): 780-786.

11. Degreef, H. (2008). Clinical forms of dermatophytosis. Mycopathologia, 166(5-6): 257265.

12. Enemour, S.C. and Amedu, A.S. (2009). Prevalence of superficial mycoses in primary school children in Anyigba, Kogi state, Nigeria. African Journal of Microbiology Research, 3(2): 62-65.

13. Enweani, I.B., Ozan, C.C., Agbonlahor, E.E. and Ndip, R.N. (1996). Dermatophytosis I school children in Ekpoma, Nigeria. Mycoses, 39: 303-305.

14. Fathi, H.I. and Al-Samarai, A.G.M. (2001). Dermatophytosis in Children: study of 137 cases. Revista do Instituto de Medicina Tropical de Sap Paulo, 43: 83-85.

15. Hainer, B.I. (2003). Dermatophyte infections. American Family Physician, 67: 101-108.

16. Havlickova, B., Czaika, V.A., Friedrich, M. (2008). Epidemiological trends in skin mycoses worldwide. Mycoses, 51(4): 2-12.

17. Mbata, T.I. and Nwajagu, C.C. (2007). Dermatophytes and other fungi associated with hair scalp of nursery and primary school children in Awka, Nigeria. The Internet Journal of Microbiology, 3(2): 1-6.

18. Moon, H., Moon, J., Lee, J., Kim, S., Won, Y. and Lee, S. (2001). Epidemiologic study of superficial fungi infection in outpatients of dermatologic clinic and healthy individuals. Chonnam Medical Journal, 37(4): 409-413.

19. Nweze, E.I. and Okafor, J.I. (2005). Prevalence of dermatophytic fungi infections in children: A recent study in Anambra state, Nigeria. Mycopathologia, 160: 239-243.

20. Nweze, E.I. (2001). Etiology of dermatophytees among children in Northeastern Nigeria. Medical Mycology, 39: 181-184.

21. Ogbu, C.C., Okwelogu, I.S. and Umeh, A.C. (2015). Prevalence of superficial fungi infection among primary school pupils in Awka South Local Government Area of Anambra State. Journal of Mycology Research, 2(1): 15-22.

22. Olaide, O.O., Olaniyi, O., Olayinka, A.O., Akinlolu, G.O. and Olumayowa, A.O. (2014). The prevalence and pattern off superficial fungal infections among school children in Ileife, South Western Nigeria. Dermatology Research and Practice, 7: 312-320.

23. Olusola Ayanlowo, Ayesha Akinkugbe, Rita Oladele, and Mobolanle Balogun. (2014). Prevalence of Tinea capitis infection among primary school children in a rural setting in South-West, Nigeria. Journal of Public Health in Africa, 5(1): 349

24. Omar, A.A. (2000). Ringworm of the scalp in primary schools children in Alexandria: Infection and carriage. Eastern Mediterranean Health Journal, 6(5-6): 961-967.

25. Oyeka, C.A. and Eze, I.I. (2008). Fungal skin infection among prison mates in Abakaliki, Nigeria. Mycoses, 51(1): 50-54.

26. Popoola, T.O., Ojo, D.A. and Alabi, R.O. (2006). Prevalence of dermatophytoses in junior secondary school children in Ogunstate, Nigeria. Mycoses, 49: 499-503. 
27. Schmeller, W., Baumgartner, S. and Dzikus, A. (1997). Dermatophytosis in children in rural Kenya: Impact of primary health care. Mycoses, 40: 55-63.

28. Seebacher, C., Bouchara, J.P. and Mignon, B. (2008). Update on the epidemiology of Dermatophyte Infections. Mycopathologia, 166(5-6): 335-352.

29. Soyinla, F. (1978). Epidemiologic study of dermatophyte infections in Nigeria (Clinical survey and laboratory investigations). Mycopathologia, 63(2): 99-103.

30. Uneke, C.J., Ngwu, B.A. and Egemba, O. (2006). Tinea capitis and pityriasis versicolor infections among primary school children in South-Eastern Nigeria: The public health implications. The internet Journal of Dermaology, 4(2). 